\title{
A Review of the Study of Poor Whites Trilogy
}

\author{
Huang Xiuguo* \\ School of Interpretation \& Translation, Shandong University, Weihai, Shandong Province, China \\ *xiuguohuang@126.com
}

Keywords: Poor Whites Trilogy;New Criticism; Faulkner

\begin{abstract}
Poor Whites Trilogy is often underestimated because of tis realist description of poor whites'economic reformation.This trend can be traced back to the exemplification of Cleanth Brooks' criticism.The Poor Whites Trilogy with its concern for and its close interaction with the contemporary society, made Faulkner's individual voice heard.
\end{abstract}

\section{Introduction}

Faulkner's Poor Whites Trilogy, with the Snopeses, the title family, as an exemplification of the newly ascending force in Post-bellum, and particularly their chief man Flem Snopes' economic reformation and its everlasting influence. In the current and established criticism, the Poor Whites Trilogy, to a certain extent, is often underestimated due to its inconsistency with and also divergence from the experimental and avant-garde magnum opus produced in Faulkner's “Ten Year”.

Faulkner's writing career is usually divided into three periods: the apprenticeship (1920s); the period of prodigious output (1930s); the later period (1940s and 1950s). The previously mentioned canonical studies are mainly concerned with the works of The Poor Whites Trilogy was produced in Faulkner's later period. The majority of the existing criticism centers on topics like grand mythological themes, racial issues and experimental narrative techniques in his "major" works. In the skillful delineation of what took place in his time, Faulkner excogitated his influence as the "social conscience" instead of retreating into a self-imagined world of art for self-nurture. Faulkner attempted to deal with the predicament encountered by the modern society-particularly the extolling of instrumental rationality and an insatiable chase for material abundance at the expense of humanity.

\section{General overview of the study of Faulkner}

Among the numerous Faulknerian scholars, three authorities with theirmonumental works demand our particular attention. For a start, Malcolm Cowley, on whose compilation of The Portable Faulkner (1946) Faulkner's literary reputation mainly rested, made a great contribution to the propagation of Faulkner's writings. In the preface to The Portable Faulkner, Cowley presented an incisive appreciation of Faulkner's achievement and set a basic tone for the subsequent criticism. He claimed that Faulkner "invent(ed) a Mississippi county that was like a mythical kingdom, ... and made his story of Yoknapatawpha Country stand as a parable or legend of all the deep South”.(Cowley,1985: Viii)

Later, Cleanth Brooks' The Yoknapatawpha Country (1963) and Toward Yoknapatawpha Country and Beyond (1978), by virtue of close reading, examined themes of provinciality, ethics, role of community, southern slavery heritage and contrast between the old order and the new, which to a large extent established the keynote for the following decades. Cleanth disrupted the sequence of Faulkner's works and created a mythical kingdom of his own. Compared with Malcolm Cowley, Cleanth further pointed out that Yoknapatawpha transcended the Southern locality and proved to be a universal allegory of the whole world. Another authoritative reviewer was Andre Bleikasten, the French translator of Faulkner's works. His magnum opus The Ink of Melancholy (1990) investigated works of Faulkner's bumper period of "unbroken fertility and the creative outburst" from The Sound and the Fury to Light in August. (Bleikasten, 1990: xi) 
In the shadow of these colossuses, other voices are also heard. Different from the initial and canonical studies on Faulkner, more and more Faulkner research is conducted from the views of gender, identity, race and ideology. For example, since the 1990s gender-centered criticism has yielded great fruits. The traditional gender analysis usually centered on the female characters, the four stereotypes: the melancholy and detached Southern Belle, the tragic mulatto, the loyal black nannies and the dauntless confederate women. Recently, gender study has extended to scrutiny of masculinity, feminized males and sexual preference. Both Minrose Gwin' The Feminine and Faulkner (1990), which employed Lacanian psychoanalysis, and Deborah Clarke's Robbing the Mother (1994) aided by the theory of Kristeva explored the defiant force of certain female characters in a patriarchal world. Diana Roberts in Faulkner and the Southern Womanhood (1994) analyzed Faulkner's deconstructive efforts to break down the dichotomy of male-female category. Doreen Fowler in Faulkner: the Return of the Repressed (1997) in light of Lacanian theories demonstrated how the marginalized female and blacks revealed the forbidden desire. Race studies also contributed to new findings in Faulkner research. The recent trend from this perspective usually focused on the comparison between Faulkner and Morrison, which has nowadays "become an industry". (Bassett, 2009: 5) For example, Erick Dussere made an incisive examination of how slavery tropes acquired aesthetic form in the two world renowned masters' fictions in Balancing the Books: Faulkner, Morrison, and the Economies of Slavery (2003). Ideological studies usually combined materialist perspective with post-structuralism. For example, Richard Godden's Fictions of Labor (2007) based his analysis of Faulkner's work on the slave-based and race-based economy from the antebellum to the New Deal.

Recently there is also a new birth of Faulkner's biographies and annotations to his work. Joseph Blotner published and republished his one-volume version of Faulkner's Biography in 1991 and 2005. Jay Parini also rendered a very readable, insightful and sensible overview of Faulkner in his biography of Faulkner. Noel Polk with his meticulous textual analysis and psychoanalytic insights became a central figure in study of Faulkner in the 1990s. Lately he also published line by line commentaries and glossaries to Faulkner' s works, like Reading Faulkner. Light in August: Glossary and Commentary (1994), Reading Faulkner. The Unvanquished: Glossary and Commentary (1995), Reading Faulkner. The Sound and the Fury: Glossary and Commentary (1996), Reading Faulkner. Sanctuary: Glossary and Commentary (1996) and Reading Faulkner. Absalom, Absalom!: Glossary and Commentary (2010), which furnished incisive interpretations for Faulkner readers and researchers.

\section{Overview of the study of Poor Whites Trilogy}

The existence of the unbalanced attention paid to Faulkner's works is most clearly embodied in the fact that among 300 more or less doctoral dissertations on Faulkner written by doctoral candidates in America from 1989 to 2013, no more than 10 dissertations are primarily concerned with the Poor Whites Trilogy. Malcolm Cowley once observed that Faulkner's early novels when not condemned were over praised for wrong reasons. In fact, many of Faulkner's later novels are ridiculed or simply neglected for wrong reasons, too. As Toni Morrison stated "with few exceptions, Faulkner criticism collapses the major themes of that writer into discursive 'mythologies' and treats the later works-whose focus is race and class-as minor, superficial, marked by decline”.(Morrison, 1993: 14) Even today, this trend of generalization of the Poor Whites Trilogy hasn't met real challenges, which is testified by the scarcity of the publications on these novels. For example, based on the statistics, from 2000 to 2010, "Faulkner Journal" an authoritative and specialized periodical on Faulkner study published about 100 papers on Faulkner and his works. Among them, there are only two articles on Poor Whites Trilogy: "Monuments and Footprints: the Mythology of Flem Snopes”(2001) by Owen Robinson and “Testing Masculinity in the Snopes Trilogy" (2008) by Noel Polk.

This trend can be traced back to the exemplification of Cleanth Brooks' criticism of Faulkner. Undoubtedly Cleanth Brooks' study of Faulkner's works is immeasurable and prolific, and its 
contribution to the propagation of Faulkner's achievement and the further establishment of Faulkner's literary status is unprecedented. However, any theory, while being incisive, is also restrictive. Cleanth's New Criticism creed limited his as well as other later-followers'critical perspectives. "New Critical and historicalperspectives have viewed Faulkner's work as disinterested in thepolitical and social conditions of his time". (Miles, 2008: 325) Their focus is on the narrative point of view, allusion, experimental and avant-garde narrative technique and form. Those works that are inconsistent with this school of literature appreciation, especially Faulkner's later works like the Poor Whites Trilogy are undervalued. But there are scholars like Morris Tien who is aware that "there can be no doubt that the final evaluation of William Faulkner's literary achievement will rest upon all his works dealing with Yoknapatawpha County and its people”. (Tien, 1982: 1) As a chronicle of the Snopes family in Frenchman's Bend and Jefferson town over a span of about 34 years in the creation of Yoknapatawpha, the Poor Whites Trilogy, shouldn't be neglected.

The first volume of the trilogy The Hamlet was published in 1940. The next two volumes appeared separately in 1957 and 1959. As a group, the three books with a span of nineteen years traced the process of social transformation in Yoknapatawpha County during the first half of the 20th century. Among these three books of the Poor Whites Trilogy, The Hamlet was most highly valued because of its humor, tall-tale tradition and "playful eccentricities of form and style", particularly "the conunterpointing of essentially separate narratives in a single book, the arts of modulation...... (and) the complex mixture of modes or tones”. (Guerard,1982: 205) Many critics took it as a continuation of Faulkner's prime writing period, a book “complete in itself” (Tien, 1982: 11). When The Hamlet first appeared in 1940, most of the reviewers noticed its narrative strength, humor and the "tall tale" tradition that was typical of the South West Frontier. And "many reviewers continue to portray Faulkner as primarily as purveyor of bizarre abnormalities and demonic violence". (Basset, 2009: 22) As to the subsequent book of the trilogy, The Townwas considered very readable but lack of the richness of a masterpiece and below the standard of Faulkner's major fiction. Alfred Kazen complained that in The Town the Snopeses no longer a myth or grotesquely comic characters had become merely a symbol or a weak rubber stamp. Even the loyal admirer Malcolm Cowley called it the dullest book. The Mansion, which wrapped up the Poor Whites Trilogy, published in November 1959, was considered an assertion of the failure of Faulkner's gifts, the exhaustion of his perception and the narrowing of his canvas. Many critics believed that there was a gradual decline of literary achievement in this trilogy. Read in sequence, immediately following The Hamlet and The Town, The Mansion seemed a less vital book than either of its predecessors. In The Mansion the first-person narrativebecame "tedious and evenimaginatively unpersuasive despite the liveliness of the account of old Meadowfill and the hog”.(Cowley, 1985: 37) The Town had been considered a lesser work than The Hamlet, and very different in tone and techniques.

To many critics, repetition and discontinuity in characterization further corroborates the deterioration of Faulkner's literary creation. As a particular brand of Faulkner's writing, repetition is not peculiar to the Poor Whites Trilogy. It is materialized in many of his widely acclaimed masterpieces. Repetition is not a sign of the old garrulous Faulkner, but is employed to unify the three books and substantiate the coherence of the trilogy. The Hamlet is a collection of several previously published short stories without a compact plot despite the association between its characters. Repetition is employed to unify the divergent stories in The Hamlet. Also through repetition, happenings in the three novels become coherent. For example, there is the story of Montgomery Ward Snopes in The Town and The Mansion, and the retelling and supplementation of Mink's story in the trilogy. At the same time it is more than repetition but is also progressiveness and refutation. Faulkner wrote a special preface to The Mansion to clarify the discrepancies in repetition and "contradiction in the thirty four-year progress of the chronicle ... (is) due to the fact the author has learned more about the human heart and its dilemma”. (M 9) This can also be considered as an affirmation of the progressiveness in his characterization of poor whites, such as Mink Snopes. 
In America the Poor Whites Trilogy has been mainly treated by critics in their full-lengthstudies of Faulkner's works as a whole, such as Cleanth Brooks, Michael Millgateand Olga W. Vickery. Most of the published essays are conducted from the perspectives of themes, biological concerns, intertextuality, and prototypes. The three monographs on the trilogy that merit particular attention areMan in Motion: Faulkner's Trilogy (1961)by Warren Beck,which argued that Poor Whites Trilogy was united in the theme of change in the human experience. The Snopes Dilemma: Faulkner's Trilogy (1968) by James Gray Watson stressed the conflict in human's heart.The Snopes Family and the Yoknapatawpha County: A Study of William Faulkner's Trilogy(1982) by Morris Wei-hsin Tien through detailed analysis of the episodes of these three books came to the conclusion that Snopesism was not foreign and invasive but was rooted in the community. He believed that "it is a mirror that truthfully reflects the evils that permeate society”. (Tien, 1982: 81)

Most of the study on trilogyis mainly conducted from the following perspectives: techniques and structures, social themes and ethic exploration. The early studies on The Hamlet were concentrated on its structure. Robert Penn Warren paid special attention to the "intricate patterning of contrasts" that established the structure of the novel. (Warren, 1947: 356) Edward E. Holmes' study showed how the revision in the trilogy manifested Faulkner's style. T. Y Greet analyzed the use of myth in The Hamlet. The social themes studies were usually devoted to the Faulkner's conservative and nostalgic attitude towards a disintegrating South. Malcolm Cowley said the novels to a certain extent were connected with what Faulkner regarded as "the rape and corruption of the south". (The Portable Faulkner introduction, Viii) Cleanth Brooks probed into the Southern culture to point out that Faulkner used his characters to show his defensive stance. Ethnic studies tried to show Faulkner's concern of man's moral responsibility. John Lewis Longley discussed Ratliff and Gavin Stevens' effort to keep the community mores from contamination by foreign forces represented by the Snopes clan. In their view, Faulkner's Poor Whites Trilogy described the conflict between "the maintenance of conventional values by acommunity's dominant social group and the economic and social rise ofits marginal group". (Kang, 2005: 495) Recently, due to the wane of New Criticism and flourishing of criticism that emphasized political concerns, there emerged a revision of the general disesteem of Faulkner's later works. Critics like Joseph Urgo and Theresa M. Towner challenged the established criticism and claimed that Faulkner's late works reflected a new development of his artistry, particularly an alteration in narrative and theme. Influenced by these critics, Faulkner's later works gained more and more positive affirmation.

Compared with American scholar's exploration of the Poor Whites Trilogy, Chinese academia paid even less attention to it. Of the three books of Poor Whites Trilogy, only The Hamlet is translated into Chinese by ZhangYue in 2001. The scanty comments on the trilogy are sporadically scattered in the full-length discussions of Faulkner by scholars like Li Wenjun, Xiao Minghan, Zhu Zhenwu, Li Mengyu, Li Changlei, Liu Jianhua and Li Yang. According to the author's statistics, "Signification, Dissemination and Subversion: A Deconstructive Reading of Faulkner's Snopes Trilogy" (2009), a PHD dissertation by Zhan Xiaoming of Shanghai International Studies University is the first one of its kind in China. Zhang Luning, in his PHD dissertation"The Historical Context and The Textual Representation: A Study on William Faulkner's Fiction Writing" (2013) devoted chapter 4 and chapter 5 to the discussion of the transition from agricultural civilization and industrial civilization and its representation of social strata in Faulkner's fiction. Zeng Junshan from Hunan Normal University in his PHD dissertation "The Textuality of the Snopes Trilogy" (2012) discussed the intertexualtiy between the Poor Whites Trilogy and its southern culture. Articles like "Commodities, Costume and Advertising: An Interpretation of the Consumer Culture in Faulkner'sThe Hamlet" (2010) by Han Qiqun and "Stereotypes of the Poor Whites Snopes in The Town” (2012) by Li Yang and Liu Yuhan, can be viewed as other incentive attempts for the appreciation of the Poor Whites Trilogy.

\section{Conclusion}

The relatively few commentaries on Poor Whites Trilogy have for a large part been the criticism of the inferiority of these novels in view of its conventional writing style. In fact, the Poor Whites 
Trilogy, as an incisive reflection on the social transformation, is in coherence with Faulkner's humanitarian stance. The Poor Whites Trilogy with its concern for and its close interaction with the contemporary society, made Faulkner's individual voice heard. They could rival his greatest works.

\section{References}

[1]Bassett, John E. ed. William Faulkner: An Annotated Bibliography of Criticism since 1988. Maryland: Scarecrow Press, Inc., 2009.

[2]Bleikasten, Andre. The Ink of Melancholy: Faulkner's Novels from the Sound and the Fury to Light in August. Bloomington: Indiana University Press, 1990.

[3]Cowley, Malcolm, ed. The Portable Faulkner. New York: Penguin Books, 1985.

[4]Faulkner, William. The Hamlet. New York: Random House, 1940.

[5]Guerard, Albert Joseph. The Triumph of the Novel: Dickens, Dostoevsky, Faulkner. Chicago: University of Chicago Press, 1982.

[6]Miles, Caroline. "William Faulkner's Critique of Capitalism: Reading Wash and Centaur in Brass as Stories about Class Struggle.” Mississippi Quarterly, 61: 3, pp.325-341, 2008,

[7]Morrison, Toni. Playing in the Dark: Whiteness and the Literary Imagination. New York: Vintage books, 1993.

[8]Tien, Morris Wei-hsin. The Snopes Family and the Yoknapatawpha County: a study of William Faulkner’s Trilogy. Nankang: Institute of American Culture Academia Sinica, 1982. 